Article

\title{
Passivation of Carbon Steel Using Intelligent Epoxy Paint
}

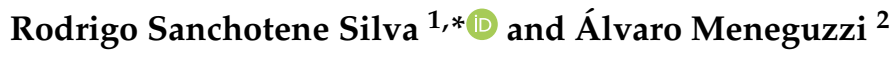 \\ 1 Materials Recovery and Treatment Laboratory, State University of Rio Grande Sul-UERGS, \\ Porto Alegre 90010-191, Brazil \\ 2 Laboratory of Corrosion, Protection and Recycling of Materials-LACOR, Department of \\ Materials-DEMAT, School of Engineering-EE, Federal University of Rio Grande do Sul-UFRGS, \\ Porto Alegre 91501-970, Brazil; meneguzzi@ufrgs.br \\ * Correspondence: rodrigo-sanchotene@uergs.edu.br
}

Received: 9 April 2020; Accepted: 27 April 2020; Published: 7 May 2020

\begin{abstract}
This paper presents the production of an epoxy paint associated with a determined concentration of PAni emeraldine base binder, in order to increase dispersion of PAni polymer chains in the paint allow physical contact between PAni chains, the electrolytic medium, and the metal of interest. The coating called Intelligent Epoxy Paint (IEP) seeks to potentialize the electrolytic capacity of PAni to produce passivation, differentiated research which uses PAni in oxidized and conductive form as paint pigment that needs high PAni concentrations. The physicochemical characterization and morphological presented results that indicate the preservation of the desirable properties of PAni in order to make the passivation process possible. The electrochemical tests showed the passivation and/or maintenance of the passivation of the metal of interest, without the need to apply an external current.
\end{abstract}

Keywords: epoxy paint; polyaniline; anodic protection; organic coating; corrosion

\section{Introduction}

The use of organic coatings has been presented as an alternative for corrosion protection of metallic materials in harsh environments. Currently, the industrial production of organic coatings with anticorrosive capacity is consolidated with the use of inorganic inhibitors. These components $(\mathrm{Zr}, \mathrm{Cr}$, $\mathrm{Pb}, \mathrm{Zn}$ and others) have as an inconvenience the possible environmental contamination and human health due to their toxic and/or carcinogenic nature [1-3].

Intrinsically Conductive Polymers (ICP) can offer advantages that enable environmental compatibility and properties that minimize or slow down the corrosive process. In addition, the use of ICP in organic coatings can result in savings in electricity consumption, as they could totally or temporarily replace rectifiers that are used for the application of printed current to form and maintain passivation of oxidizable metals [1,4].

ICP polyaniline (PAni) has aroused significant interest in the scientific and technological environment for years due to the low cost characteristics of the monomer (aniline), the ease of synthesis, the excellent stability under certain environmental conditions in both non-conductive and conductive form, the ability to become electronic and ionic insulator in the oxidized state, representing desirable properties for the production of barrier effect in coatings and enabling the oxidation reactions capable of forming and/or preserving passivating oxides for various passivable metals, in addition to possessing properties that make it possible to obtain free-standing films $[1,4,5]$.

Oxidated and doped (conductive) PAni, known as protonated emerald (PAni EP), has been used in most research to produce organic coatings as part of the pigment, dispersed in a conventional 
polymer matrix, a fact that makes it difficult or reduces performance in the formation or maintenance of protective oxides in metallic substrates. Oxidated and nonconductive PAni, known as emerald base (PAni EB), allows the formation of a self-supporting coating, which, besides forming or maintaining the passivation of the metallic material, can increase the barrier effect, preventing physical contact of the metal with the aggressive medium [6,7].

This work proposes the production of a binder consisting of PAni EB, an electrochemically inert plasticizer and a solvent. Obtaining the binder starts with the production of PAni EP and, subsequently, its passage to $\mathrm{PAni} E \mathrm{~EB}$, through the process of undoped. Then, the binder is formed by the combination of PAni EB, the plasticizer 4-chloro-3-methylphenol (CMP), and solvent dichloromethane $\left(\mathrm{CH}_{2} \mathrm{Cl}_{2}\right)$. Subsequently, the PAni EB binder produced is mixed with an epoxy commercial paint (CEP) and a commercial epoxy resin (CER) in sufficient quantities so that its polymer chains come into physical contact with each other and the metal and electrolyte surface $\left(\mathrm{H}_{2} \mathrm{SO}_{4}\right)$ [8].

Thus, this study aims to evaluate the possibility of the anodic protection of AISI 1010 steel provided by a CEP or CER consisting of 1\% of PAni EB binder, without the application of external potential or current to the metal/coating/electrolyte system. In addition, the use of PAni in concentration is far below the methodologies that use PAni in the form of a pigment, the which allows for naming the coating produced Intelligent Epoxy Paint (IEP).

The organic coating produced will be assessed for its ability to form or maintain a surface layer of passive oxides-which, together with a possible barrier effect of the coating, may provide protection against corrosion of passivable metals, in order to replace, if not fully, the least at determined periods, the current anodic metal protection tools in harsh environments.

\section{Materials and Methods}

\subsection{PAni EP Production and the PAni EB Binder}

PAni EP synthesis was performed using a jacketed reactor with a capacity of $20 \mathrm{~L}$, with controlled agitation and cooling. The previously distilled aniline monomer at $0.4 \mathrm{~mol} \mathrm{~L}{ }^{-1}$ concentration in a $1.5 \mathrm{~mol} \mathrm{~L}^{-1} \mathrm{HCl}$ solution was chemically oxidized by the slow addition of the oxidizing agent $\left(\mathrm{NH}_{4}\right)_{2} \mathrm{~S}_{2} \mathrm{O}_{8} 0.4 \mathrm{~mol} \mathrm{~L}^{-1}$ (also in $1.5 \mathrm{~mol} \mathrm{~L}^{-1} \mathrm{HCl}$ aqueous solution). The reaction medium was kept at $-5^{\circ} \mathrm{C}\left( \pm 1^{\circ} \mathrm{C}\right)$ under stirring for $5 \mathrm{~h}$, the time required for complete addition of $\left(\mathrm{NH}_{4}\right)_{2} \mathrm{~S}_{2} \mathrm{O}_{8}$. The production of PAni EB was carried out by the PAni EP deprotonation process, where it was introduced into a $0.5 \mathrm{~mol} \mathrm{~L}^{-1}$ aqueous $\mathrm{NH}_{4} \mathrm{OH}$ solution at a ratio of 1:15 $(\mathrm{g} / \mathrm{mL})$ of PAni EP and solution, respectively. The suspension was maintained at $\mathrm{pH} 10$, under moderate agitation for $6 \mathrm{~h}$ using a magnetic stirrer. After PAni, it was filtered with the help of a Büchner funnel and washed with $0.5 \mathrm{~mol} \mathrm{~L}^{-1} \mathrm{NH}_{4} \mathrm{OH}$ solution until the filtrate was colorless. The PAni EB thus obtained that it was kiln dried at $60^{\circ} \mathrm{C}$ for $24 \mathrm{~h}[8-10]$.

PAni EB binder production was performed from the 1:2:10 mass use of PAni EB, non-doping plasticizer $\mathrm{CMP}$, and organic solvent $\mathrm{CH}_{2} \mathrm{Cl}_{2}$. The organic solvent dichloromethane $\left(\mathrm{CH}_{2} \mathrm{Cl}_{2}\right)$ was used to form a solution of PAni EB mixture with the plasticizer and to control the drying time during binder formation. These components were homogenized at a rotational speed of $1500 \mathrm{rpm}$ in a closed bottle for $6 \mathrm{~h}$ by a Dispermat Model N1 (VMA-GETZMANN GMBH, Reichshof, Germany) high rotation disperser. The product obtained was capable of forming freestanding films in which PAni EB was dispersed in the medium as a viscous liquid $[8,10]$.

\subsection{IEP Preparation}

IEP production occurred with the addition of a 1\% (w/w) PAni EB binder to a two-component CEP, with the main purpose of adding it to commercial paint anti-corrosion properties. Thus, the PAni EB binder was mixed with white CEP, which it characterizes by not undergoing significant chemical changes during the formation of the film, and a CER, without pigments and charge, was used to evaluate the behavior of a possible interference of charge or pigment on the IEP. 
In practical attempts to formulate IEP at binder concentrations above $1 \%$, the IEP samples had difficulties to obtain homogeneous mixture with PAni EB binder. Already in lower concentrations, it was possible to verify in previous works the low anti-corrosion performance of the binder [11]. The preparation of the IEP was performed with the mixture of the CEP and the PAni EB binder in a dispersion system of high rotation, with the aid of the Dispermat Model N1 high rotation disperser,

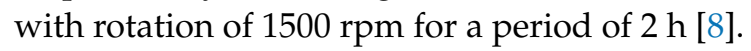

An intelligent paint (IP) was produced, through mixing a one-component CER, without addition of pigment or charge, to a 1\% PAni EB binder using dichloromethane as a solvent. The purpose of this new IP is to achieve results without a possible interference from the various components that make up the commercial inks used, where some of these could mask real PAni EB performance in corrosion protection, in addition to applying this coating to $\mathrm{Pt}$, which is theoretically immune to aggressive solutions. This paint was called IP of CER. The equipment used for the production of this IP was the Dispermat Model N1 high rotation disperser, with rotation of $1500 \mathrm{rpm}$ for a period of $2 \mathrm{~h}$ [8].

\subsection{Paints Application}

For the physicochemical and morphological characterization CEP, IEP and PAni EB film were applied to Petri dishes, which, after the drying process at room temperature for a period of $48 \mathrm{~h}$, were removed using a spatula. CEP and IEP also were applied to AISI 1010 steel plates which are made up of $0.1 \%$ of $\mathrm{C}, 0.01 \%$ of $\mathrm{Si}, 0.42 \%$ of $\mathrm{Mn}, 0.01 \%$ of $\mathrm{P}, 0.007 \%$ of $\mathrm{S}, 0.033 \%$ of $\mathrm{Al}, 0.007 \%$ of $\mathrm{Cu}$, $0.004 \%$ of $\mathrm{Ni}, 0.011 \%$ of $\mathrm{Cr}, 0.001 \%$ of $\mathrm{Mo}, 0.001 \%$ of $\mathrm{V}, 0.004 \%$ of $\mathrm{N}, 0.001 \%$ of $\mathrm{Ti}$ and $0.0001 \%$ of $\mathrm{B}$, as indicated by the manufacturer. IP of CER was applied to $\mathrm{Pt}(99.9 \%)$ plates, with the aid of $200 \mu \mathrm{m}$ spacers, connected to the Automatic Film Applicator BYK-Gardner (BYK Gardner, Wesel, Germany) equipment, using the speed of $250 \mathrm{~mm} \mathrm{~s}^{-1}$. After the proof, bodies went through the drying process at room temperature for a period of $48 \mathrm{~h}$.

The AISI 1010 steel parts and Pt parts, in the dimensions of $10 \mathrm{~cm} \times 5 \mathrm{~cm}$ and $5 \mathrm{~cm} \times 2.5 \mathrm{~cm}$ respectively, before being coated, passed the alkaline degreasing process, using the Saloclean 619L commercial degreaser, which is a composed of sodium salts, emulsifiers, nonionic surfactants, and humectants. The purpose of this process is to clean the steel parts by removing oils, greases, and other contaminants from their surface in order to obtain a degreased surface.

The metal parts were immersed in Saloclean 619L solution at a concentration of $5 \% \mathrm{w} / \mathrm{v}$ at a temperature of $45^{\circ} \mathrm{C}$ for a period of $900 \mathrm{~s}$. Subsequently, the parts were washed with deionized water jets and air jet dried at a temperature of approximately $60^{\circ} \mathrm{C}$. The impurity free plates were intended for the application of IEP, CEP, and IP of CER.

\section{Experimental}

\subsection{Physicochemical and Morphological Characterizations}

The thicknesses of the IEP and CEP films which coat AISI 1010 steel were measured with the aid of the Fischer Dualscope MP20 model (Windsor, CT, USA). Raman Spectrometry equipment used was the Micro-Raman-Labram-Horiba/Jobin Yvon spectrometer (Trenton, NJ, USA) equipped with a multichannel detector of 1024 diode, colds by the Peltier effect. We used the $632.8 \mathrm{~nm}$ excitation beam from a Spectra-Physics Model 165 ionized Helium-Neon laser (Sheaumann, Marlborough, MA, USA).

Superficial morphological analysis in the CEP and IEP samples was performed by Scanning Electron Microscopy (SEM) coupled with the technique of Dispersive Energy Spectroscopy (EDX), which use the $10 \mathrm{keV}$ JEOL 5800 microscope (Tokyo, Japan) coupled with X-ray Noran EDX. For the EDX technique, CEP and IEP coated AISI 1010 steel samples were metallized with Au and Pt, respectively, and the use of different metals in metallization process does not interfere with the practical results of the analysis. 


\subsection{Electrochemical Studies}

The electrochemical tests were performed with at least three repetitions for each type of sample and technique used. The equipment used was the Potentiostat/Galvanostat AUTOLAB PGSTAT302 Ecochemie (Eco Chemie, Netherlands). Three electrochemical testing techniques were used: Cyclic Voltammetry (CV), Open Circuit Potential (OCP), and Electrochemical Impedance Spectroscopy (EIS). The results obtained were treated by two software programs: GPES for VC and OCP assays and FRA for EIE assays.

The electrochemical tests were conducted in $2 \mathrm{~mol} \mathrm{~L}^{-1}$ aqueous solution of $\mathrm{H}_{2} \mathrm{SO}_{4}$, at temperature and ambient aeration, without agitation, using electrochemical cells of three electrodes, where the AISI 1010 steel and Pt, after the degreasing process, with or without coating, was used as working electrode, the silver/silver chloride $(\mathrm{Ag} / \mathrm{AgCl})$ electrode as reference electrode, and platinum wires $(99.99 \% \mathrm{Pt})$ as counter-electrode.

The reference electrode was associated with a Luggin capillary at a distance of about $1 \mathrm{~mm}$ from the working electrode, aiming to decrease the ohmic drop produced by the electrolyte, the electrode exposure area to $0.62 \mathrm{~cm}^{2}$, and the counter electrode; the most noble and inert metal has an area of $1.52 \mathrm{~cm}^{2}$.

\section{Results and Discussion}

\subsection{Thickness Measurement}

CEP samples applied using a $200 \mu \mathrm{m}$ spacer had an average thickness of $178.43 \mu \mathrm{m}$ with a standard deviation of $34.67 \mu \mathrm{m}$. IEP samples applied using a $200 \mu \mathrm{m}$ spacer had an average thickness of $150.88 \mu \mathrm{m}$ with a standard deviation of $31.67 \mu \mathrm{m}$. Figure 1a,b show automatic film applicator BYK-Gardner and an AISI 1010 steel sample.

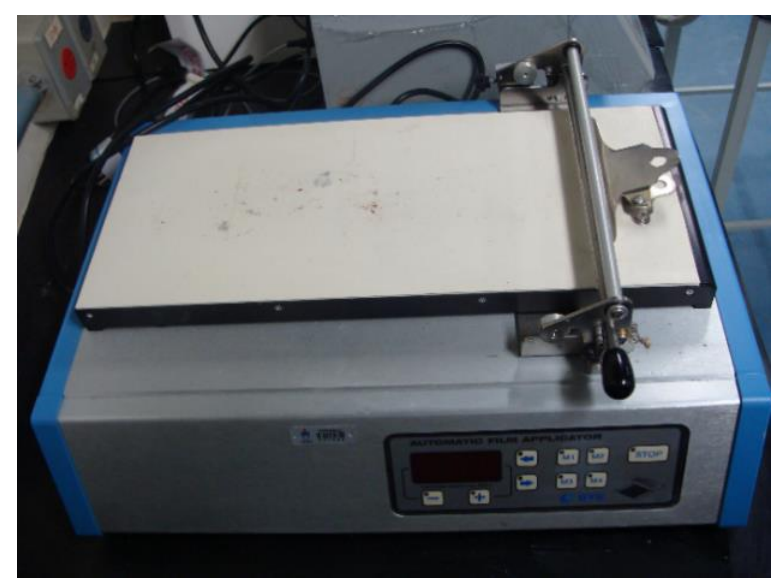

(a)

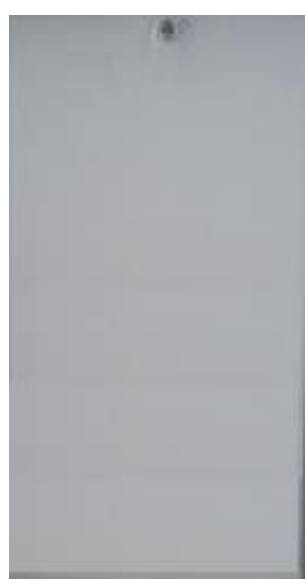

(b)

Figure 1. (a) automatic film applicator BYK-Gardner, with dimensions of $56.6 \mathrm{~cm} \times 20.3 \mathrm{~cm} \times 31 \mathrm{~cm}$, and (b) AISI 1010 steel sample, with dimensions of $10 \mathrm{~cm} \times 5 \mathrm{~cm}$.

From the results obtained, it is possible to observe that the use of spacers with maximum measurements of $200 \mu \mathrm{m}$ may have interfered with the samples' thickness. In addition, the presence of the PAni EB binder may have interfered with the decrease in the thickness of the film produced in relation to CEP, but that its standard deviation is within a region of thickness that is very close to the average CEP thickness, which represents a non-significant thickness variation to influence it in electrochemical test results. 


\subsection{Raman Spectroscopy}

PAni EB, CMP, and PAni EB binder samples were analyzed by Raman Spectroscopy and the spectra are shown in Figure 2 and Table 1. The binder spectrum is similar to a typical PAni EB spectrum, where the band at $1628 \mathrm{~cm}^{-1}$, attributed to the $\mathrm{CC}$ benzenoid ring stretch and another band at $1588 \mathrm{~cm}^{-1}$, corresponds to the $\mathrm{C}=\mathrm{C}$ elongation of the quinoid ring. The bands at 1492 and $1465 \mathrm{~cm}^{-1}$ are attributed to the $\mathrm{C}=\mathrm{N}$ stretch of oxidized PAni, the band $1412 \mathrm{~cm}^{-1}$ to the $\mathrm{CC}$ stretch of the quinoid ring, the band at $1218 \mathrm{~cm}^{-1}$ to the $\mathrm{C}-\mathrm{N}$ stretch, and the deformation of quinoid ring $\mathrm{C}-\mathrm{H}$ appears in $1165 \mathrm{~cm}^{-1}$ [12-14].

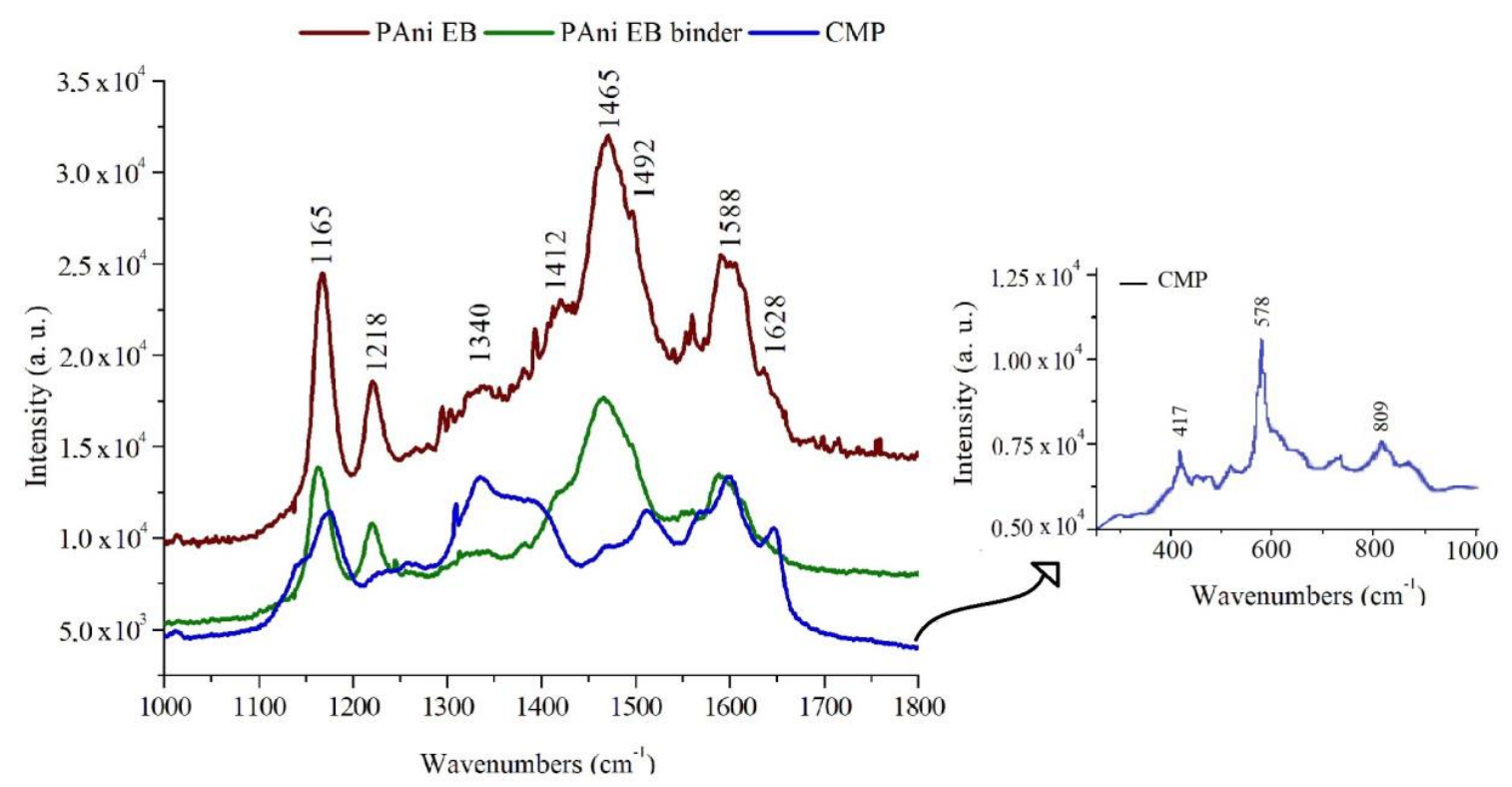

Figure 2. Raman spectrum of PAni EB, PAni EB binder, and CMP.

Table 1. Raman spectroscopy for PAni EB, PAni Binder, and CMF samples.

\begin{tabular}{ccc}
\hline Samples & Bands $\left.\mathbf{( c m}^{-\mathbf{1}}\right)$ & Correspondent \\
\hline & 1628 & Stretch C-C of benzoid ring \\
& 1588 & Elongation C=C of the quinoid ring \\
PAni EB and Binder of PAni EB & $1492-1465$ & Stretch C=N of oxidized PAni \\
& 1412 & Stretch C-C of quinoid ring \\
& 1218 & Stretch C-N \\
& 1165 & Deformation C-H of quinoid ring \\
\hline \multirow{2}{*}{ CMP } & 1390 & Angular stretch $-\mathrm{CH}_{3}$ \\
& 1340 & Axial deformations of the links C-O \\
& $400-800$ & Links C-Cl and C-O \\
\hline
\end{tabular}

As shown in Figure 2 and Table 1, CMP has certain peaks close to those of PAni EB because the molecule has aromatic characteristics. The differentiation of the samples occurs with the presence of bands in the region of 400 to $800 \mathrm{~cm}^{-1}$, which characterize the presence of $\mathrm{C}-\mathrm{Cl}$ and $\mathrm{C}-\mathrm{O}$ bonds. The band in the $1340 \mathrm{~cm}^{-1}$ region is attributed to the axial deformations of the $\mathrm{C}-\mathrm{O}$ bonds that are associated with the aromatic ring and the $1390 \mathrm{~cm}^{-1}$ band is attributed to the $-\mathrm{CH}_{3}$ angular stretch $[12,15]$.

The Raman analyses of the PAni EB and the PAni EB binder present similar bands, previously described, that characterize the oxidized and non-conductive PAni, the PAni EB. The reduced state of PAni is related to the conformational changes that occur in the quinoid and benzenoid rings, which are attributed to changes in the 1588 and $1165 \mathrm{~cm}^{-1}$ bands of the oxidized state of PAni, something not shown in Figure 2. In case the PAni is in the protonated state, the Raman spectrum should have a band 
in the region of 1300 to $1350 \mathrm{~cm}^{-1}$, which would characterize the quinonic stretch $\mathrm{C}-\mathrm{N}^{+}$, which is attributed to the protonated form of the PAni EP, a fact that is not observed in PAni EB film [16-18]. With the obtained spectra, it can be stated that the PAni EB present in the binder remains in the oxidized state.

Thus, it was possible to observe that the CMF does not act reduction or protonation the PAni present in the binder produced. The plasticizer does not induce alteration in the oxidized and insulating state of PAni EB, which is a necessary condition for its future use as a component of some protective coating that promotes the anodic protective effect on passivable metals, and associated with the barrier effect produced by the coating.

As shown in Figure 3 and Table 2, the CEP and IEP samples showed similar spectra, with the presence of band in the $1097 \mathrm{~cm}^{-1}$ region that can be attributed to the $-\mathrm{CH}_{2}-$ groups that are present in the TBI. Intensity peaks at $1184 \mathrm{~cm}^{-1}$ correspond to aliphatic glycidyl groups (COC) characteristic of epoxy resins, but for IEP samples can also be attributed to PAni EB C-N bonds. Bands in the $1441 \mathrm{~cm}^{-1}$ region are attributed to the presence of $\mathrm{OH}$ groups of $\mathrm{CEP}$, and to IEP samples can be associated with $\mathrm{C}-\mathrm{N}$ bonds of PAni EB binder. The bands at $1603 \mathrm{~cm}^{-1}$ represent the presence of $\mathrm{C}=\mathrm{C}$ bonds in CEP aromatic rings for the three samples $[13,15,18]$.

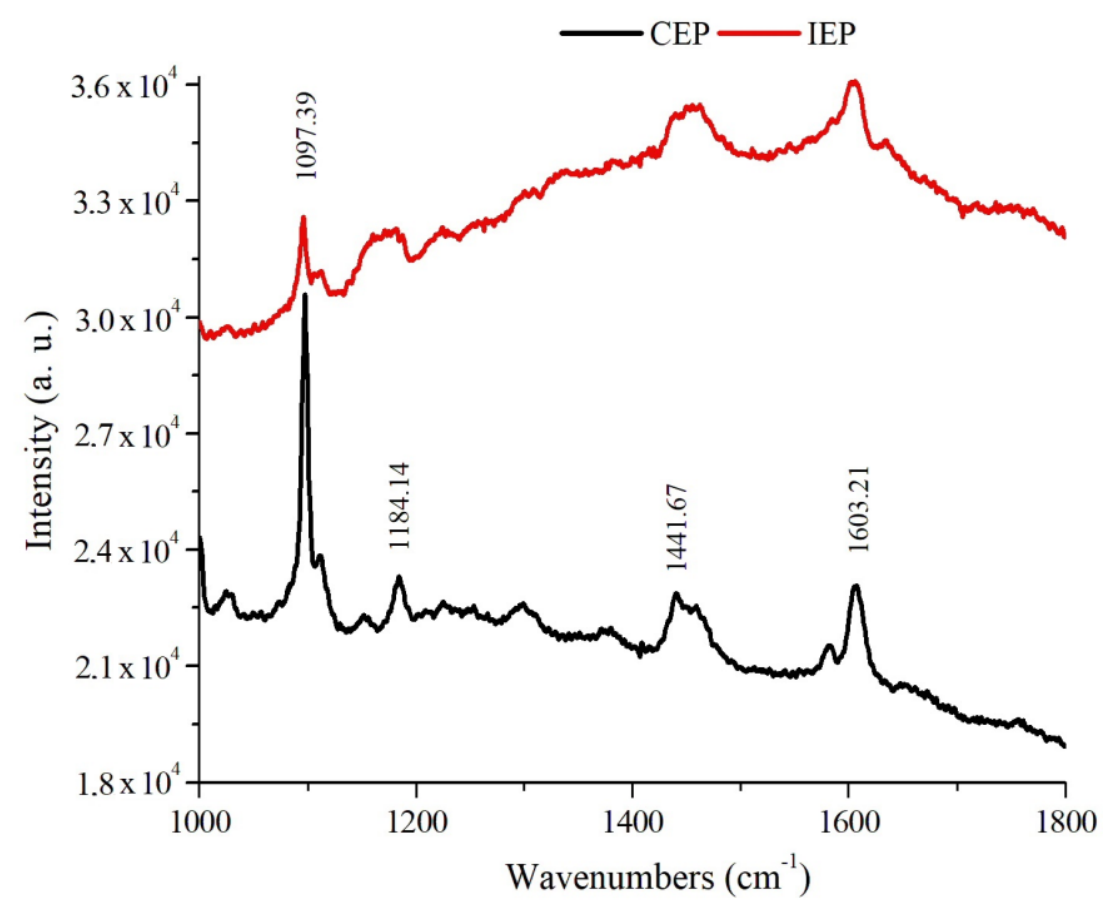

Figure 3. CEP and IEP Raman spectrum.

Table 2. Raman spectroscopy for CEP and IEP samples.

\begin{tabular}{ccc}
\hline Samples & Bands $\left(\mathbf{c m}^{-\mathbf{1}}\right)$ & Correspondent \\
\hline & 1097 & Groups $-\mathrm{CH}_{2}-$ \\
CEP and IEP & 1184 & Aliphatic glycidyl groups $(\mathrm{COC})$ or links C-N \\
& 1441 & Groups OH or links $\mathrm{C}-\mathrm{N}$ \\
& 1603 & links $\mathrm{C}=\mathrm{C}$ \\
\hline
\end{tabular}

Raman analyses for the IEP samples did not show spectra that indicate the presence of PAni binder in CEP that modifies the structural characteristics of the PAni EB polymer chain, as some intensity peaks characterize the presence of PAni EB binder if it overlaps with CEP characteristic links, which are associated with the low concentration of the PAni EB binder and the CEP for the formation of the IEP, make it difficult to identify a possible chemical interaction of the PAni EB binder and the CEP, which 
could alter the oxidized and non-conductive state of the PAni, due to the chemical variability of the components that make up a commercial paint.

\subsection{Scanning Electron Microscopy/Dispersive Energy Spectroscopy}

The CEP micrograph, shown in the SEM image in Figure 4a-c, presents a relief altering morphology, which shows the presence of dark and light regions, which were evaluated by EDX, at points 1 (P1) and 2 (P2). The EDX spectra of P1 and P2 have chemical elements characteristic of the CEP forming resin, such as $\mathrm{C}, \mathrm{O}$, and the presence of pigments and fillers, such as $\mathrm{Ba}, \mathrm{Ca}, \mathrm{Al}$, and $\mathrm{Si}$ [19]. The presence of a characteristic excitation peak of $\mathrm{Au}$ is attributed to the metallization process.

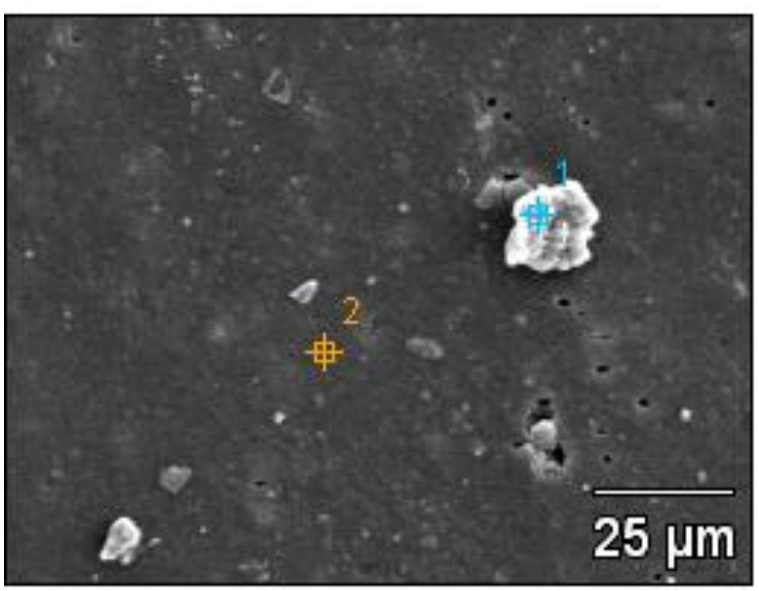

(a)

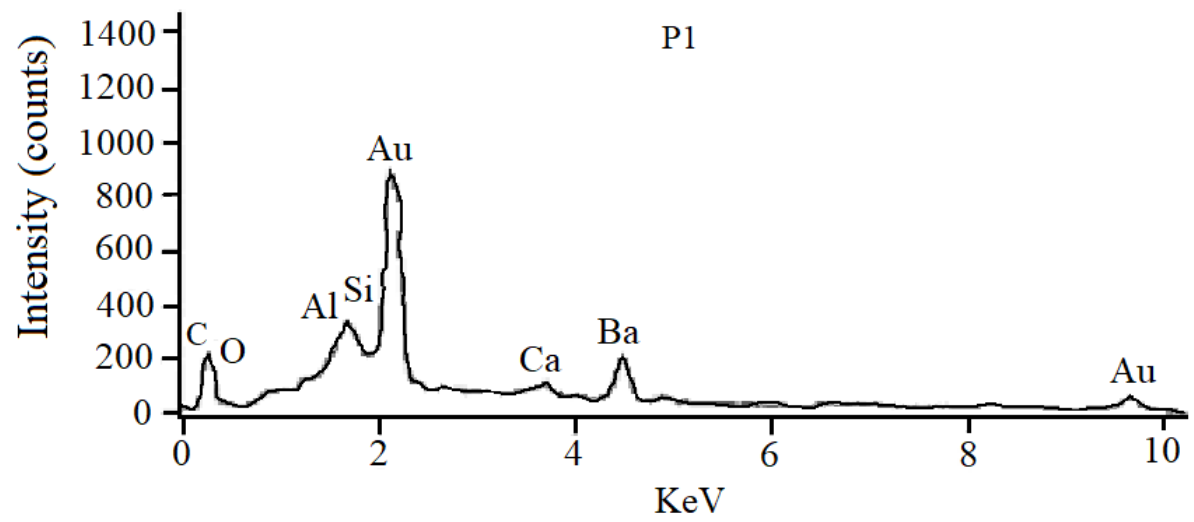

(b)

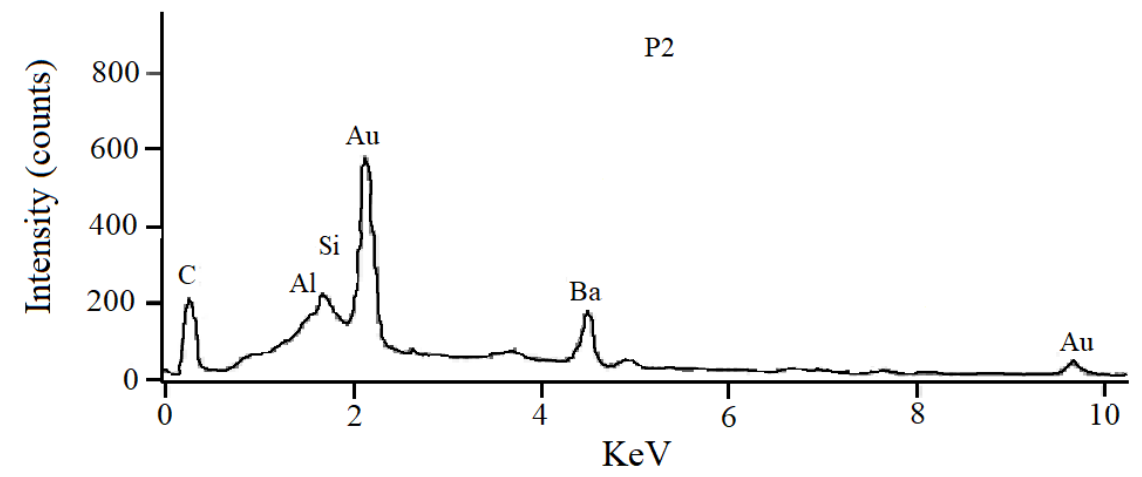

(c)

Figure 4. (a) SEM of the surface of a CEP film with 1000× magnification. The EDX is from two film surface analysis locations, (b) P1 and (c) P2. 
The surface micrograph of an IEP film, shown in the SEM image in Figure $5 a-c$, shows a film with homogeneous distribution of its constituents. EDX analysis performed on the IEP sample, at the P1 and P2 sites, indicates, beyond the presence of the characteristic chemical elements of the CEP used, the presence of the $\mathrm{N}$ element that corresponds to the presence of the PAni EB contained in the IEP forming binder, and the presence of the $\mathrm{Cl}$ element assigned to the CMP of PAni EB binder that is contained in the IEP, also confirming that the PAni EB binder is dispersed in the coating produced [11]. The presence of a characteristic peak excitation of $\mathrm{Pt}$ is attributed to the metallization process.

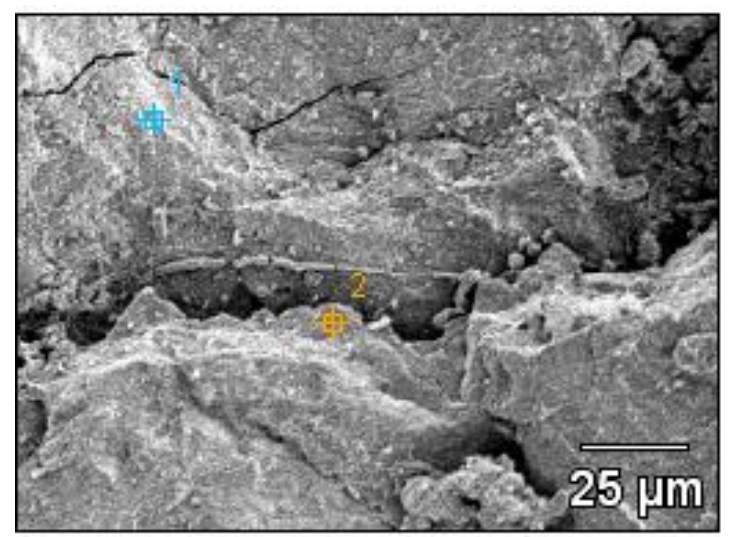

(a)

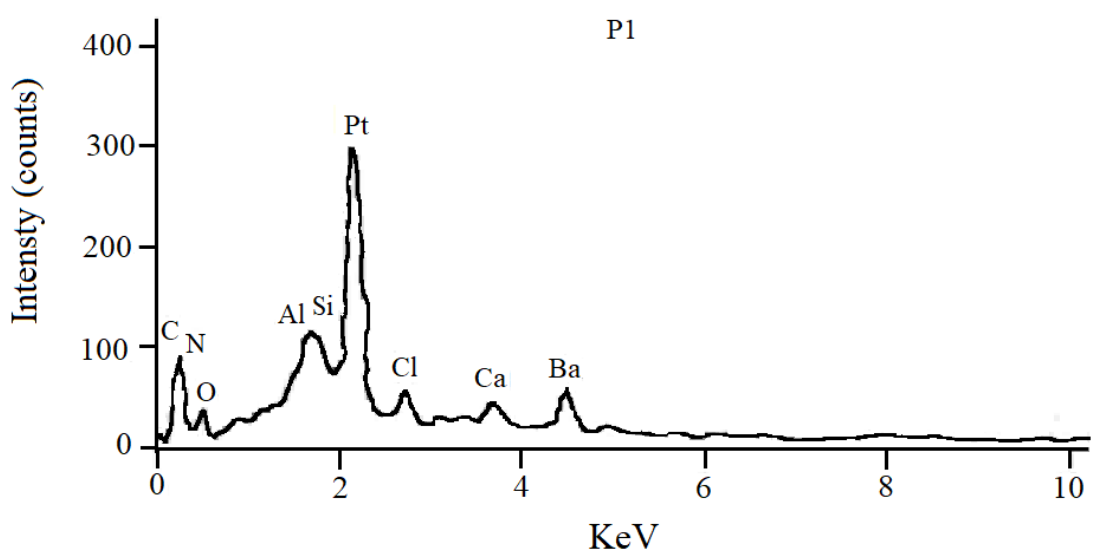

(b)

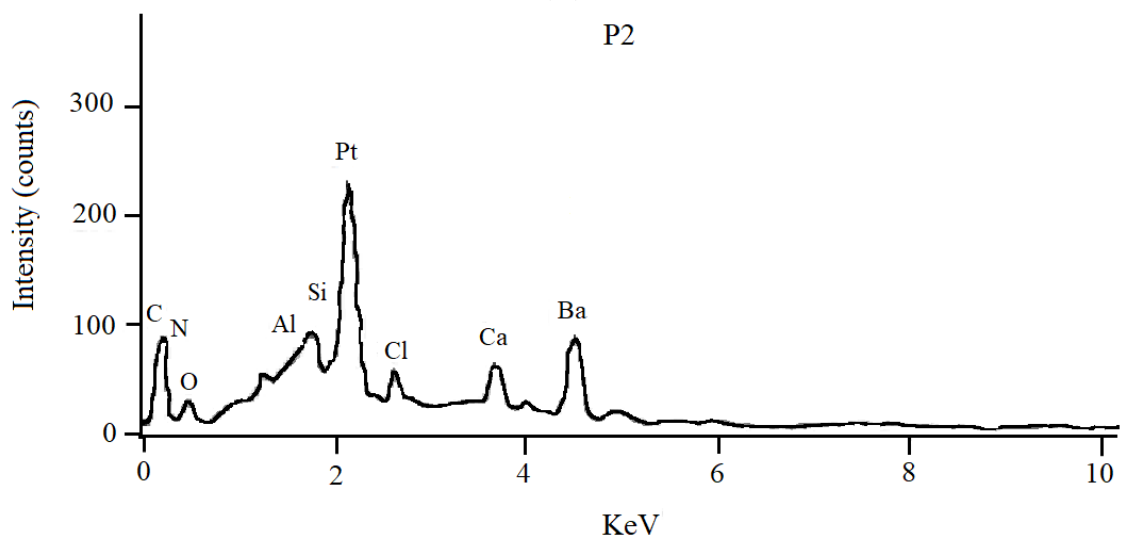

(c)

Figure 5. (a) SEM of the surface of a IEP film with $1100 \times$ magnification. The EDX is from two film surface analysis locations. (b) P1 and (c) P2. 
SEM/EDX assays gave answers indicating that at least part of the PAni EB binder was dispersed for IEP formation because the PAni EB binder that forms IEP is observed in micrometric points, without the presence of particles in the form of pigments.

\subsection{Cyclic Voltammetry Assay}

CV tests were performed on samples of uncoated AISI 1010 steel and samples of uncoated $\mathrm{Pt}$ in order to identify potential values that represent the oxidation and reduction regions at the metal/coating/electrolyte interface, and which consequently result in the formation of a protector's oxide surface layer in these metals, i.e., the passivation of the metal. The metals were submerged to aqueous solution of $2 \mathrm{~mol} \mathrm{~L}^{-1}$ of $\mathrm{H}_{2} \mathrm{SO}_{4}$.

As observed in Figure 6a, CV analysis was performed on AISI 1010 steel from the (round-trip) potential scan of -1.00 to $+2.00 \mathrm{~V}_{\mathrm{Ag} / \mathrm{AgCl}}$, the rate of $25 \mathrm{mV} \mathrm{s}^{-1}$, where it was observed that the potential from -1.00 to $-0.50 \mathrm{~V}_{\mathrm{Ag} / \mathrm{AgCl}}$ represents a cathodic active region (reduction) in which the metal is immune to the electrolyte medium. Later, the potential reaches an anodic active region (oxidation), which represents the corrosion of the metal $[8,20]$.

From the $+0.39 \mathrm{~V}_{\mathrm{Ag} / \mathrm{AgCl}}$ potential, the metal passivation region begins, with the presence of the Flade Potential, where current density stabilization $\left(\mathrm{I}\left(\mathrm{A} \mathrm{cm}^{2}\right)\right.$ ) occurs, indicating the formation of a compact and adherent layer of iron oxides. After the potential $+1.75 \mathrm{~V}_{\mathrm{Ag} / \mathrm{AgCl}}$, the transpassivation process occurs that allows the evolution of oxygen in the form of gas [20]. Thus, it can be said that the AISI 1010 steel is passive when submitted to an aqueous solution of $\mathrm{H}_{2} \mathrm{SO}_{4}$ at a concentration of $2 \mathrm{~mol} \mathrm{~L}^{-1}$, within a potential region of +0.39 to $+1.75 \mathrm{~V}_{\mathrm{Ag} / \mathrm{AgCl}}$.

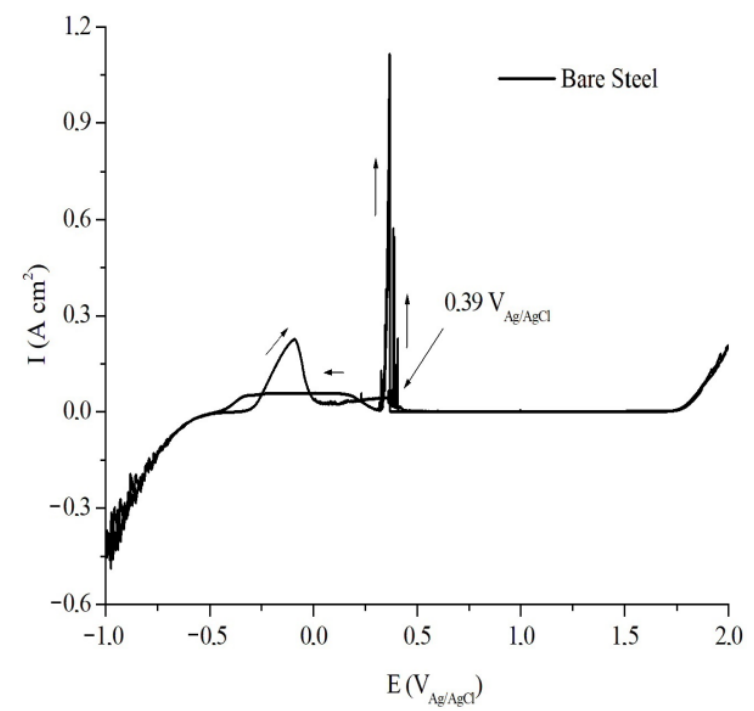

(a)

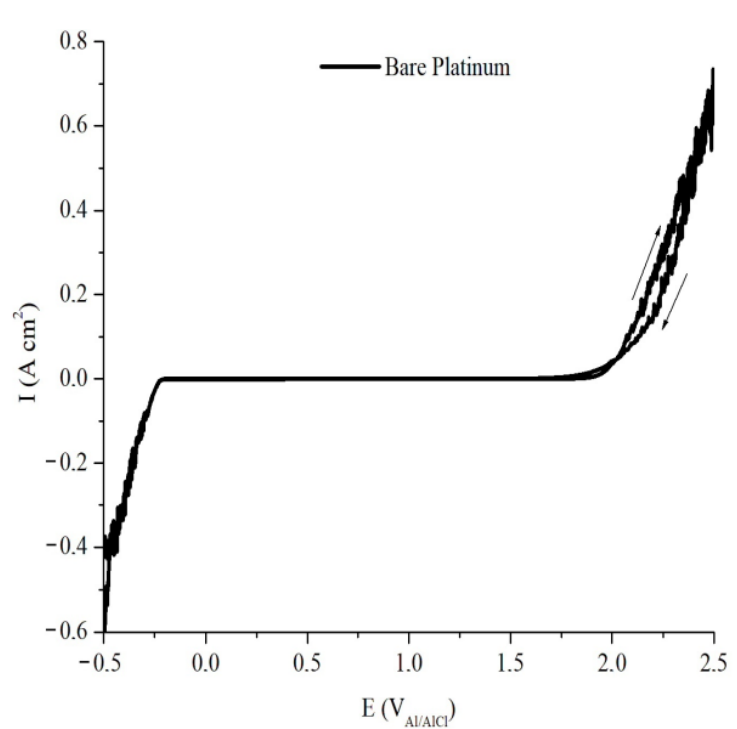

(b)

Figure 6. Voltammograms of (a) uncoated AISI 1010 steel, between -1.00 to $+2.00 \mathrm{~V} \mathrm{Ag} / \mathrm{AgCl}$; and (b) uncoated $\mathrm{Pt}$, between -0.50 to $+2.50 \mathrm{~V}_{\mathrm{Ag} / \mathrm{AgCl}}$, in solution $2 \mathrm{~mol} \mathrm{~L}^{-1}$ of $\mathrm{H}_{2} \mathrm{SO}_{4}$ aqueous solution.

The analysis of $\mathrm{CV}$ was performed in the uncoated $\mathrm{Pt}$, shown in Figure $6 \mathrm{~b}$, for which the potential scan occurred from -0.50 to $+2.50 \mathrm{~V}_{\mathrm{Ag} / \mathrm{AgCl}}$ with a rate of $25 \mathrm{mV} \mathrm{s}^{-1}$, where it was observed that the potential of -0.50 at $-0.30 \mathrm{~V}_{\mathrm{Ag} / \mathrm{AgCl}}$ represents a cathodic active region (reduction) in which the metal is immune to the electrolyte medium. Between the potentials of -0.30 to $+1.75 \mathrm{~V}_{\mathrm{Ag} / \mathrm{AgCl}}$, the region of immunity continues, where there is stabilization of current density I $\left(\mathrm{A} \mathrm{cm}^{2}\right)$, which indicates a stable region of potential that allows the evaluation of a possible performance of the proposed coating. 
CV results for the working metals, AISI 1010 steel and $\mathrm{Pt}$, allow us to infer that it is possible to use coatings with electrochemical properties such as the produced IEP, and that they could promote the anodic protection of these metals.

\subsection{Open Circuit Potential Assay}

OCP x time electrochemical characterization tests were performed on uncoated AISI 1010 steel and coated AISI 1010 steel sample with CEP and IEP. OCP $x$ time measurement of samples uncoated $\mathrm{Pt}$ and coated $\mathrm{Pt}$ with CER and IP of CER was also performed to verify the electrochemical capacity of the PAni EB binder contained in commercial coatings, which could allegedly interfere with their electrochemical properties due to their constituents. The assays were performed during the period in which the maintenance of the potential of passivation of metal occurred, to the period in which potential levels that characterize the corrosion of the metal are reached.

OCP determination was required to verify the potential values over time in the metal/coating/ electrolyte interfaces, where responses with potential values beyond the potential of Flade indicate the passivated state, or for potential values below the potential of Flade, out of passivation condition.

As shown in Figure 7a, the OCP measurements for the uncoated AISI 1010 steel sample showed, of constant form, a potential value of $-0.41 \mathrm{~V}_{\mathrm{Ag} / \mathrm{AgCl}}$ throughout the assay, indicating that the metal is in the process of being corrosion installed because it is the region of potential in which the corrosion process of the metal exposed to this electrolyte occurs, according to the CV analysis in Figure 6a [21]. The CEP coated carbon steel sample had an initial potential of around $+0.15 \mathrm{~V}_{\mathrm{Ag} / \mathrm{AgCl}}$ at time $467 \mathrm{~s}$, which can be attributed to the barrier effect produced by the commercial coating; afterwards, a decay to potential $-0.42 \mathrm{~V}_{\mathrm{Ag} / \mathrm{AgCl}}$ reached in $7150 \mathrm{~s}$, which is within the oxidation potential range of the metal corrosion characteristic installed and maintained until the end of the analysis, can be attributed to the failure of the barrier effect produced by the commercial coating.

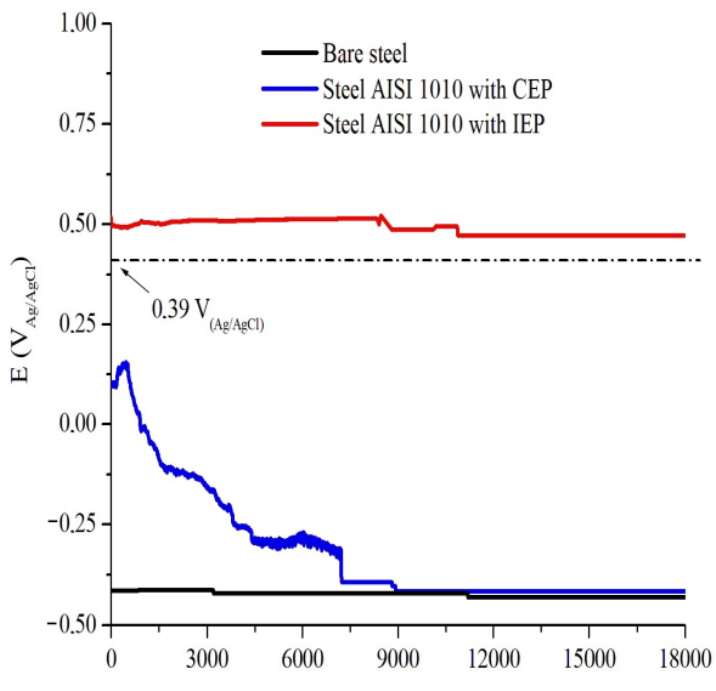

(a)

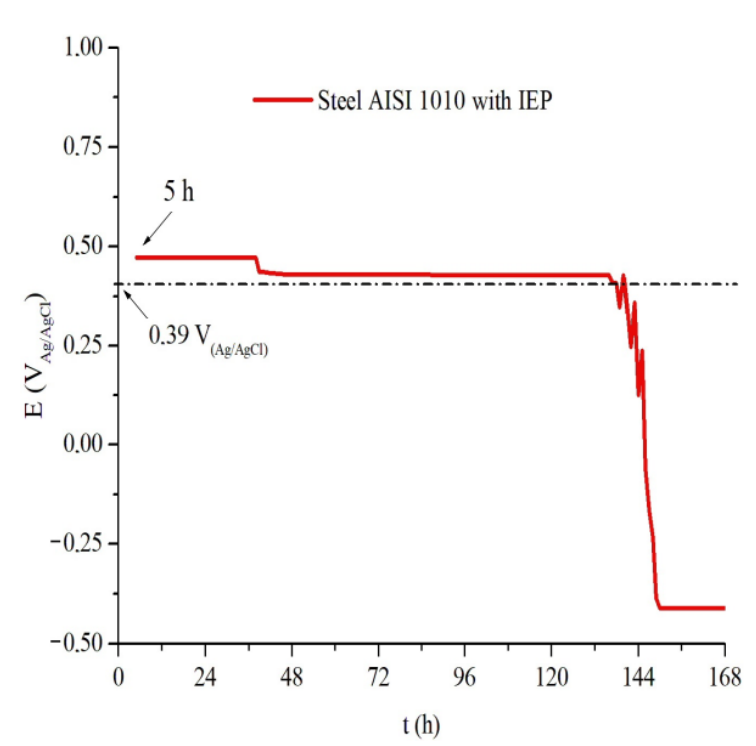

(b)

Figure 7. OCP vs. time (a) AISI 1010 steel without and with CEP, IEP coatings exposed to $2 \mathrm{~mol} \mathrm{~L}^{-1}$ $\mathrm{H}_{2} \mathrm{SO}_{4}$ solution for a period of 18,000 s; (b) AISI 1010 steel with IEP coatings exposed to $2 \mathrm{~mol} \mathrm{~L}^{-1}$ $\mathrm{H}_{2} \mathrm{SO}_{4}$ solution for a period of $168 \mathrm{~h}$. The dotted line at $0.39 \mathrm{~V} \mathrm{Ag} / \mathrm{AgCl}$ indicates the Flade potential for steel in this medium.

IEP coated AISI 1010 steel showed instantaneous decay to the potential $+0.49 \mathrm{~V}_{\mathrm{Ag} / \mathrm{AgCl}}$, and then the potential stabilized at $+0.46 \mathrm{~V}_{\mathrm{Ag} / \mathrm{AgCl}}$ over $10,968 \mathrm{~s}$, as shown in Figure $7 \mathrm{a}$. In Figure $7 \mathrm{~b}$, the continuity of the previous test for longer times is observed and the maintenance of the potential until $140 \mathrm{~h}$; after this period occurs, there is a gradual decay of the potential until the time $148 \mathrm{~h}$, reaching the 
potential of $-0.40 \mathrm{~V}_{\mathrm{Ag} / \mathrm{AgCl}}$, no longer rising until the end of the assay. The behavior of this analysis indicates that the IEP sample has a period of $140 \mathrm{~h}$ under potential conditions above the Flade Potential $\left(+0.39 \mathrm{~V}_{\mathrm{Ag} / \mathrm{AgCl}}\right)$, i.e., in the passivation region, shown in Figure 6a. The OCP decay can be attributed to the rupture of the protective oxide layer and the total reduction of PAni, indicating the end of the IEP acting period [4,21].

Figure 8 shows the OCP vs. time assay of the uncoated $\mathrm{Pt}$ and coated $\mathrm{Pt}$ with CER, average thickness of $165 \mu \mathrm{m}$, and IP of CER, with average thickness of $145 \mu \mathrm{m}$, where the samples were exposed to aqueous solution of $2 \mathrm{~mol} \mathrm{~L}^{-1} \mathrm{H}_{2} \mathrm{SO}_{4}$. Uncoated $\mathrm{Pt}$ behavior during the test was the instantaneous initial decay to the potential value of $+0.28 \mathrm{~V}_{\mathrm{Ag} / \mathrm{AgCl}}$, remaining until the end of the analysis; this potential indicates Pt oxidation in this medium.

Coated Pt with CER, Figure 8 shows an immediate initial decay to the potential $+0.24 \mathrm{~V}_{\mathrm{Ag} / \mathrm{AgCl}}$, with a gradual increase in potential until the end of the analysis, to the potential $+0.29 \mathrm{~V} \mathrm{Ag} / \mathrm{AgCl}$. This result allows us to affirm that the presence of CER does not give any protection against corrosion to $\mathrm{Pt}$, and not even the barrier effect of coating itself or electrochemical actuation, since the CER coated $\mathrm{Pt}$ has the same potential region as the uncoated Pt.

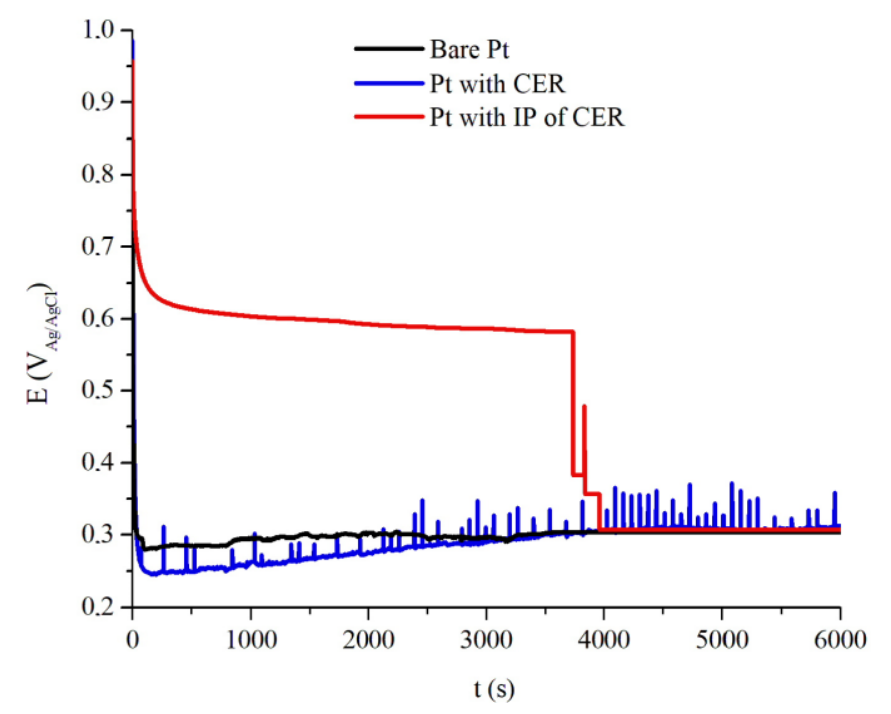

Figure 8. OCP vs. time of $\mathrm{Pt}$ with and without coatings of CER and IP of CER, exposed to aqueous solution of $2 \mathrm{~mol} \mathrm{~L}^{-1} \mathrm{H}_{2} \mathrm{SO}_{4}$.

The samples of coated Pt with IP of CER had a mild decay of potential at the start of the assay until the potential of $+0.58 \mathrm{~V}_{\mathrm{Ag} / \mathrm{AgCl}}$, until $3757 \mathrm{~s}$, when a sharp decay starts until $+0.28 \mathrm{~V}_{\mathrm{Ag} / \mathrm{AgCl}}$, identical to the potential of the uncoated sample. During the time period $3757 \mathrm{~s}$ and $3949 \mathrm{~s}$, the potential decay is associated with the presence of potential elevation peaks, an aspect that can be attributed to the end of the intelligent paint containing an electrochemical PAni ability to promote oxidation and reduction reactions in the interface electrolyte/coating/metal. This result demonstrates that the presence of the PAni EB binder in the CER gives Pt a more noble electrochemical condition compared to the CER sample and uncoated.

Figure 9a shows an image of an IEP coated AISI 1010 steel sample that was intentionally scratched to perform the OCP assay over an area without a barrier effect of the coating. The purpose of this process is to verify only the electrochemical action of the coating without possible "help" that the barrier effect provided by the coating may cause in the study against corrosion. 


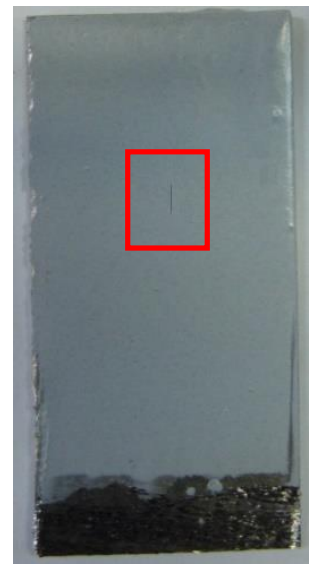

(a)

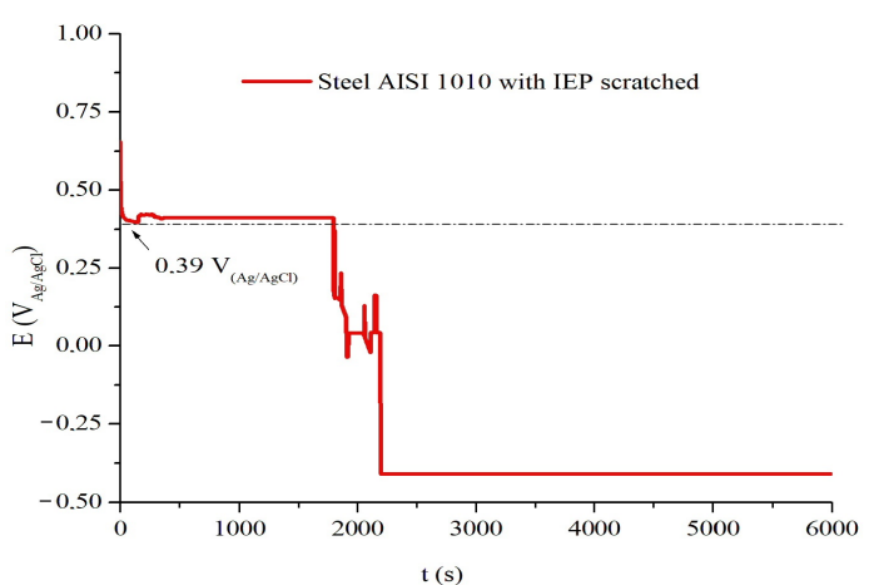

(b)

Figure 9. (a) image of the IEP coated AISI 1010 steel plate containing an failure intentional in coating; (b) OCP vs. time of AISI 1010 steel with scratched IP of CER coatings, exposed to aqueous solution of $2 \mathrm{~mol} \mathrm{~L}^{-1} \mathrm{H}_{2} \mathrm{SO}_{4}$.

OCP assay of the AISI 1010 steel sample coated defective IP of CER, shown in Figure 9b, has an initial decay to the potential of $+0.41 \mathrm{~V}_{\mathrm{Ag} / \mathrm{AgCl}}$, for which the potential remained until $1797 \mathrm{~s}$. This potential region can be attributed to the formation of the protective oxide layer on the metal surface, triggered by the oxidation and reduction reactions produced in the medium/IP/metal system. Later, there is a gradual decay of potential, with the presence of potential elevations, and decreases in a discontinuous manner, until reaching $-0.40 \mathrm{~V}_{\mathrm{Ag} / \mathrm{AgCl}}$. This process indicates that, after $1797 \mathrm{~s}$, PAni EB no longer has electrochemical capacity to promote the formation and/or maintenance of protective oxides, as it has been totally reduced, and thus the metal is exposed to the action of the medium, that is, in the degradation phase by the corrosion process.

OCP analysis of IP of CER shows that the IEP containing the PAni EB binder provides corrosion protection of AISI 1010 steel subjected to $2 \mathrm{~mol} \mathrm{~L}^{-1}$ aqueous $\mathrm{H}_{2} \mathrm{SO}_{4}$ solution not as a barrier effect but as an active ingredient. This result proves the action of the anodic corrosion protection provided by IEP, which maintained the potential in a region above the Flade Potential for 1797 s, without the presence and aid of a possible barrier effect.

\subsection{Electrochemical Impedance Spectroscopy}

Electrochemical characterization tests of the EIS were performed on uncoated $\mathrm{Pt}$ and coated $\mathrm{Pt}$ samples with the CER and IP of CER, and on uncoated AISI 1010 steel and coated AISI 1010 steel samples with CEP and IEP. Measurements made on AISI 1010 steel and Pt when coated were performed according to the possible acting of IP of CER and IEP in anodic metal protection when immersed in aqueous solution of $2 \mathrm{~mol} \mathrm{~L}^{-1}$ of $\mathrm{H}_{2} \mathrm{SO}_{4}$, shown in Figure 7. Figure 8 shows that the evaluated frequency range was $10^{5} \mathrm{~Hz}$ to $10^{-2} \mathrm{~Hz}$, with a $10 \mathrm{mV}$ synodal signal.

Initially, an EIS assay of uncoated $\mathrm{Pt}$, represented by the Nyquist diagram of Figure 10, was performed during the $0.25 \mathrm{~h}$ exposure period in aqueous solution of $2 \mathrm{~mol} \mathrm{~L}^{-1}$ of $_{2} \mathrm{SO}_{4}$, where the measured OCP potential $\left(E_{O C P}\right)$ was $+0.29 \mathrm{~V}_{\mathrm{Ag} / \mathrm{AgCl}}$, characteristic of $\mathrm{Pt}$, where it an incomplete arc with a resistance value of $2.75 \times 10^{6} \Omega \mathrm{cm}^{2}$ was observed. This spectrum indicates that the sample has a protection against the oxidation process, due to the presence of a surface layer of protective oxides attributed to $\mathrm{Pt}$ passivation, since the value of actual impedance is quite high when compared to a metal such as steel. After the $24 \mathrm{~h}$ exposure period, the $E_{O C P}$ was at the potential value $+0.28 \mathrm{~V}_{\mathrm{Ag} / \mathrm{AgCl}}$, and the obtained spectrum represents a semicircle with resistance value on the order of $1.00 \times 10^{6} \Omega . \mathrm{cm}^{2}$, indicating a decrease of protection by the natural oxides of $\mathrm{Pt}$, but still with high resistance values when compared to ordinary values of metals not considered noble. 


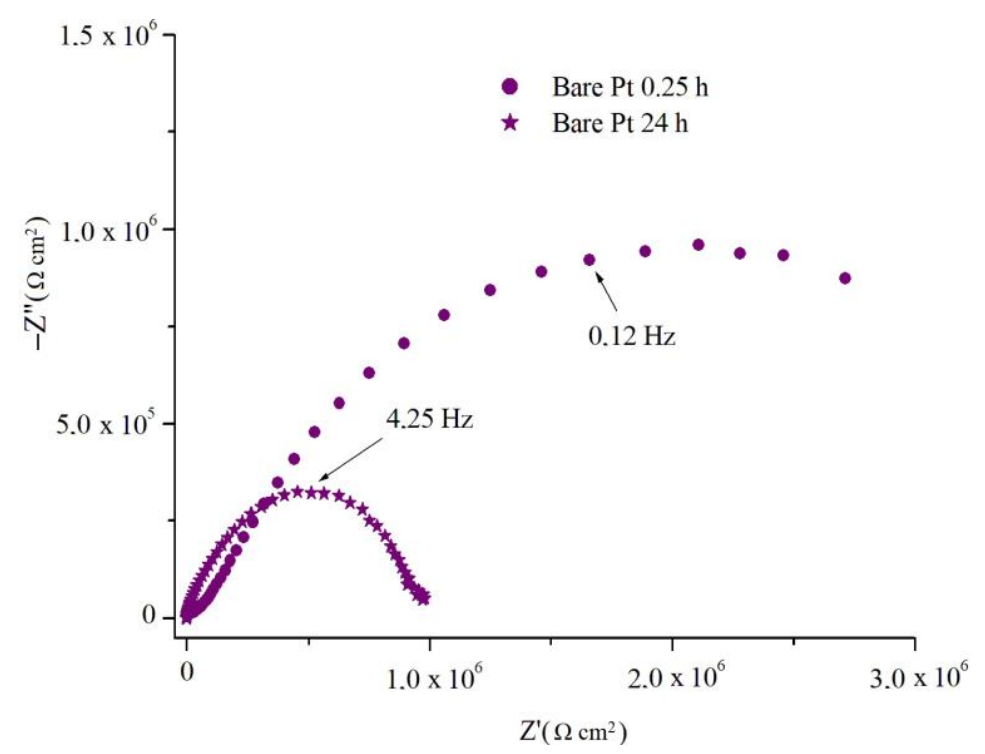

Figure 10. EIS in representation of Nyquist for uncoated $\mathrm{Pt}$, after $0.25 \mathrm{~h}$ and $24 \mathrm{~h}$ of immersion in aqueous solution of $2 \mathrm{~mol} \mathrm{~L}^{-1}$ of $\mathrm{H}_{2} \mathrm{SO}_{4}$.

EIS assay for the CER coated Pt sample was immersed in a $2 \mathrm{~mol} \mathrm{~L}^{-1} \mathrm{H}_{2} \mathrm{SO}_{4}$ aqueous solution for $0.25 \mathrm{~h}$, with the $E_{O C P}$ measured at $+0.27 \mathrm{~V}_{\mathrm{Ag} / \mathrm{AgCl}}$. As shown in Figure 11, the obtained spectrum has a resistance arc in the order of $2.5 \times 10^{8} \Omega \mathrm{cm}^{2}$, which can be attributed to the barrier effect produced by the coating, as this result represents a resistance of two orders of magnitude higher. The CER coated $\mathrm{Pt}$ sample was immersed for $24 \mathrm{~h}$ in $2 \mathrm{~mol} \mathrm{~L}^{-1} \mathrm{H}_{2} \mathrm{SO}_{4}$ solution with $E_{O C P}$ of $+0.29 \mathrm{~V}_{\mathrm{Ag} / \mathrm{AgCl}}$, where the spectrum obtained had a resistance arc of $7.5 \times 10^{6} \Omega \mathrm{cm}^{2}$.

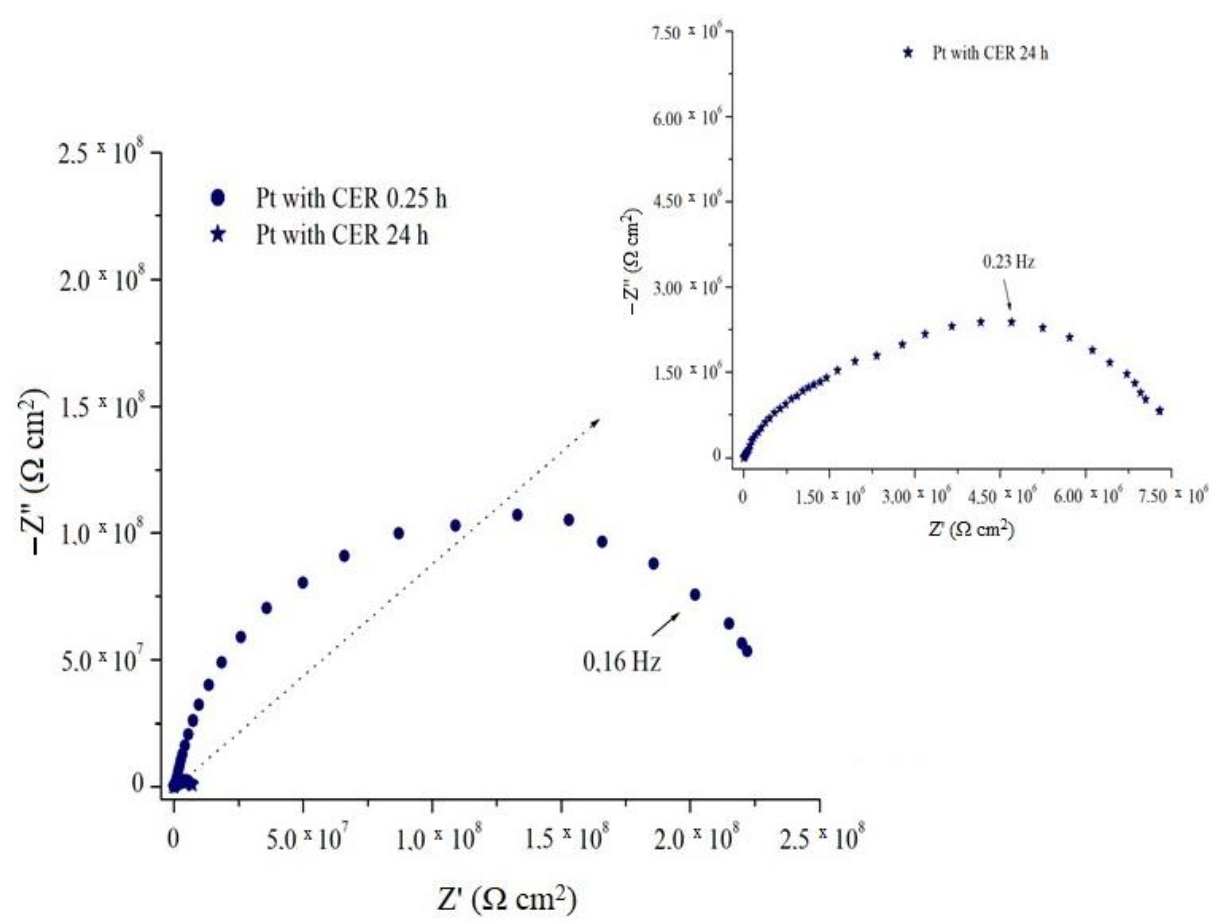

Figure 11. EIS in representation of Nyquist for CER coated Pt after $0.25 \mathrm{~h}$ and $24 \mathrm{~h}$ immersion in $2 \mathrm{~mol} \mathrm{~L}^{-1} \mathrm{H}_{2} \mathrm{SO}_{4}$ solution.

These results indicate that the samples have a higher resistance than the uncoated sample after $24 \mathrm{~h}$ exposure in $2 \mathrm{~mol} \mathrm{~L}^{-1} \mathrm{H}_{2} \mathrm{SO}_{4}$ solution. Spectra obtained in the EIS assay for the CER coated metal 
sample indicate that there is possibly a barrier effect, even flawed, which provides greater electrical and/or ionic resistance than the uncoated sample.

For the coated Pt with IP of CER (Figure 12a,b), an EIS assay showed an $\mathrm{E}_{\mathrm{OCP}}$ value of $+0.49 \mathrm{~V} \mathrm{Ag} / \mathrm{AgCl}$ for a $0.25 \mathrm{~h}$ exposure period in $2 \mathrm{~mol} \mathrm{~L}^{-1} \mathrm{H}_{2} \mathrm{SO}_{4}$ solution, and produced a spectrum with three distinct frequency regions: the first, (1) at high frequency, is represented by a value resistance arc on the order of $1.2 \times 10^{5} \Omega \mathrm{cm}^{2}$; a second region in medium frequencies (2) is indicated in the spectrum as an elevation of inclination line close to $45^{\circ}$; and a third at low frequencies (3) presents a straight line to the end of the analysis $[8,22,23]$.

The high frequency region (1) in the form of a semicircle is attributed to the process of charge and/or anion transfer in the metal/coat/electrolyte system, when charge accumulates in the coating/electrolyte system and there is a transfer of electrons from the metal for the coating and/or the medium. The region in medium frequencies (2) is attributed to the diffusion process of characteristic Warburg impedance ions, due to the transport of the $\mathrm{HSO}_{4}{ }^{-}$doping ions from the solution to the interior of the coating, which causes PAni EB doping, represented in the spectrum as the capacitive resistance increases in the system. The low frequency region (3), represented as a vertical straight line, indicates that the diffusion of ions at the metal/coat/electrolyte interface has been interrupted, and this becomes purely capacitive, which corresponds to the presence of oxides on a metal surface $[8,22,24]$.

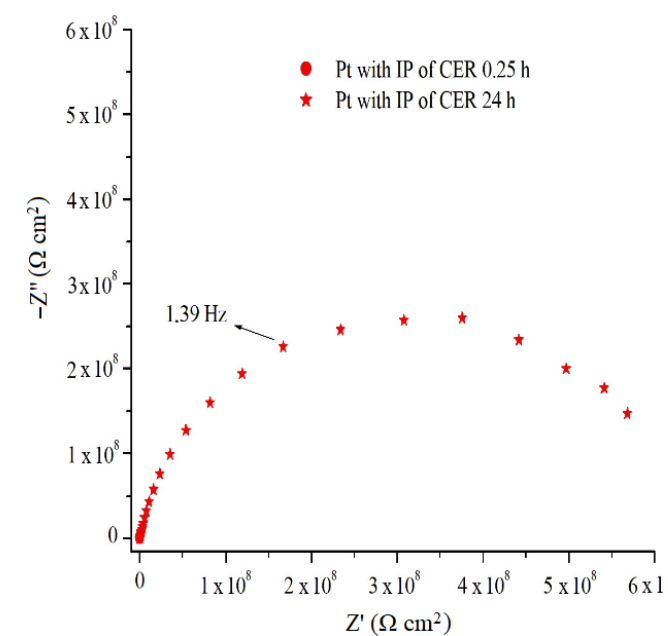

(a)

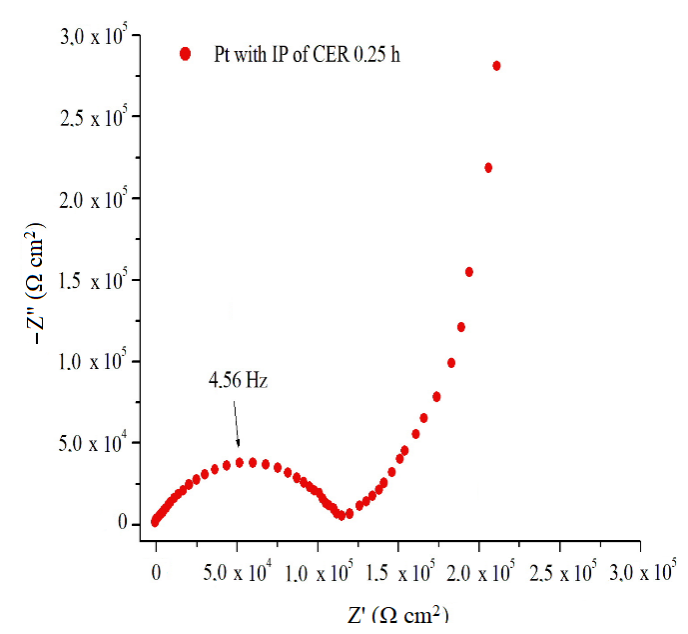

(b)

Figure 12. EIS in representation of Nyquist for coated Pt with IP of CER after (a) $0.25 \mathrm{~h}$ and $24 \mathrm{~h}$; (b) $0.25 \mathrm{~h}$ of immersion in $2 \mathrm{~mol} \mathrm{~L}^{-1} \mathrm{H}_{2} \mathrm{SO}_{4}$ solution.

Figure 12a shows the EIS assays of the coated Pt with IP de CER, after $24 \mathrm{~h}$ immersion in $2 \mathrm{~mol} \mathrm{~L}^{-1}$ $\mathrm{H}_{2} \mathrm{SO}_{4}$ solution, an $E_{O C P}$ of $+0.29 \mathrm{~V}_{\mathrm{Ag} / \mathrm{AgCl}}$ was shown, similar to uncoated Pt or uncoated of PAni EB. The sample presented spectrum with resistance arcs of $6.00 \times 10^{8} \Omega \mathrm{cm}^{2}$. This obtained spectrum has two orders of magnitude larger than the resin without PAni, for the same time of exposure to the medium, which can be attributed to the formation of a layer of thicker or more organized Pt oxides, induced by the presence of the PAni EB binder contained in the IP.

The proposed equivalent electrical circuit for representing Nyquist for IP of CER coated Pt, after $0.25 \mathrm{~h}$ exposure in $2 \mathrm{~mol} \mathrm{~L}^{-1} \mathrm{H}_{2} \mathrm{SO}_{4}$ solution, shown in Figure 13, indicates an electrolyte/coating/ metal system that is subjected to an $\mathrm{R}_{\mathrm{m}}$ of $\mathrm{H}_{2} \mathrm{SO}_{4} 2 \mathrm{~mol} \mathrm{~L}^{-1}$ solution, and that there are two simultaneous subsystems in which one Ri represents the charge transfer and/or anions of the electrolyte to the IP and $\mathrm{W}$ the diffusional process of $\mathrm{HSO}_{4}{ }^{-}$ions, increasing the capacitive resistance of the system.

$R_{e}$ represents the resistive behavior for the transport of electrons from the metal to the IP and $C_{d}$ generated at the IP border and the electrolyte medium. The IP/metal subsystem represents a constant phase element in which the behavior of IP as $C_{d}$ is conditioned on the transport of electrons from the metal to the coating [23-25]. 


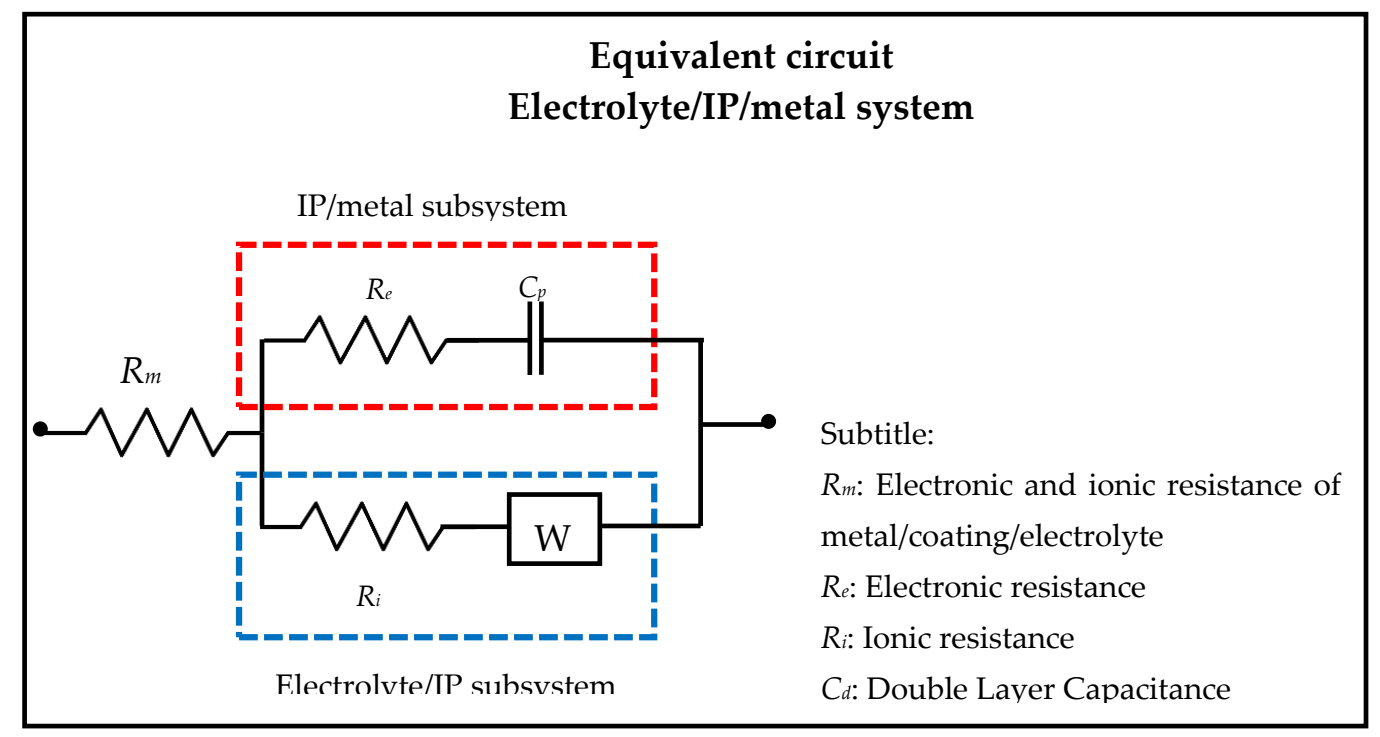

Figure 13. Equivalent electrical circuit proposed for the representation of Nyquist for Pt coated of IP of CER after $0.25 \mathrm{~h}$ of immersion in $2 \mathrm{~mol} \mathrm{~L}^{-1} \mathrm{H}_{2} \mathrm{SO}_{4}$ solution.

In order to evaluate the performance of intelligent paints isolated from the barrier effect, an EIS test was realized for samples damaged purposely, in the form of a hole up to metal surface. Figure 14a shows the EIS spectrum for the scratched IEP coated steel sample, and was performed after $0.25 \mathrm{~h}$ exposure in $2 \mathrm{~mol} \mathrm{~L}^{-1} \mathrm{H}_{2} \mathrm{SO}_{4}$ solution when the $E_{O C P}$ was $+0.42 \mathrm{~V}_{\mathrm{Ag} / \mathrm{AgCl}}$, compatible with a possible performance of IEP in anodic metal protection. The obtained spectrum can be divided into high frequency (1) and low frequency (2) regions. At high frequencies, there was a resistance arc with a value on the order of $1.05 \times 10^{6} \Omega \mathrm{cm}^{2}$, the region (1), which can be attributed to electron transfer at the metal/coating interface. In low frequency regions (2), it is possible to observe the projection of a second resistance arc with a value of $7.4 \times 10^{6} \Omega \mathrm{cm}^{2}$, which may correspond to the ion transfer at the coating/electrolyte interface. The frequency diagram shows incomplete semicircles due to the high speed at which charge transfer occurs in the metal/coating/electrolyte system [22,24].

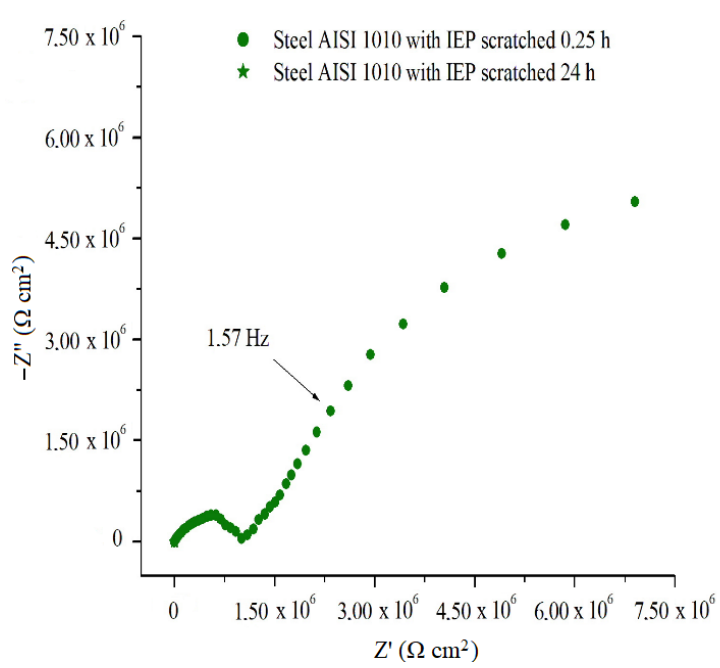

(a)

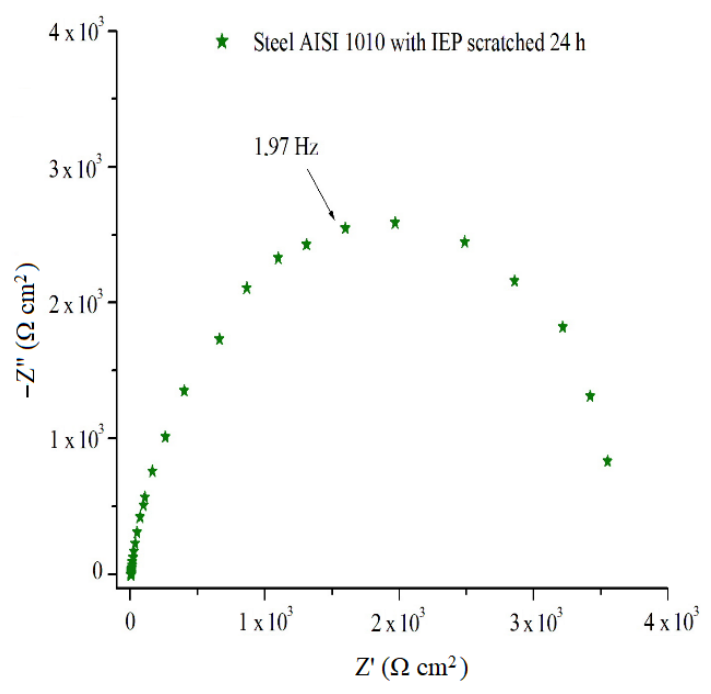

(b)

Figure 14. EIS in representation of Nyquist for scratched IEP coated AISI 1010 steel after (a) $0.25 \mathrm{~h}$ and $24 \mathrm{~h}$; (b) $24 \mathrm{~h}$ immersion in $2 \mathrm{~mol} \mathrm{~L}^{-1} \mathrm{H}_{2} \mathrm{SO}_{4}$ solution. 
The EIS spectrum for the scratched IEP coated steel sample, after $24 \mathrm{~h}$ of electrolyte exposure, Figure $14 \mathrm{~b}$, when the $\mathrm{E}_{\mathrm{OCP}}$ was at $-0.40 \mathrm{~V}_{\mathrm{Ag} / \mathrm{AgCl}}$, shown in Figure $7 \mathrm{a}, \mathrm{b}$, has a resistance arc on the order of value $3.72 \times 10^{3} \Omega \mathrm{cm}^{2}$. The diagram obtained can be attributed to the presence of failure of the protective oxide layer on the metal surface, which is characteristic of a possible past passivation, and that IEP no longer has the electrochemical capacity to promote redox pair formation in the metal/coating/middle interfaces, and thereby promote passivation.

EIS results for IEP coated AISI 1010 steel samples, purposely produced defective, for the exposure period of $0.25 \mathrm{~h}$ in the $2 \mathrm{~mol} \mathrm{~L}^{-1} \mathrm{H}_{2} \mathrm{SO}_{4}$ solution allow us to indicate a possible acting of the PAni EB binder mixed in CER to promote the passivation of metal, even in uncoated areas, but close to the coating.

\section{Conclusions}

According to the proposed objectives, from the production of PAni EP and its passage through the doping process to the PAni EB, it was possible to produce a PAni EB binder using the solvent $\mathrm{CH}_{2} \mathrm{Cl}_{2}$ and the plasticizer CMP, which has no properties that may interfere with the desired characteristics of the PAni, according to the physicochemical results presented. SEM/EDX morphological analysis showed results that indicate the presence of the PAni EB binder in the IEP.

The results presented in the OCP assay indicated that the IEP and IP of CER presented a potential region, for a certain period, being within the passivation region of AISI 1010 steel and Pt exposed to $2 \mathrm{~mol} \mathrm{~L}^{-1}$ aqueous $\mathrm{H}_{2} \mathrm{SO}_{4}$ solution. EIS tests showed results indicating that the presence of the PAni EB binder in the studied commercial coatings provides electrochemical properties that promote or maintain the formation of insoluble protective oxides on the studied metal surfaces due to the ability of PAni EB to oxidize the metal inside its range of passivation potentials in the studied environment.

The results of physicochemical, morphological and electrochemical analyses indicate that the use of PAni in the oxidized and non-conductive state may form an IEP capable of promoting the anodic protection of a passivable metal in a given electrolyte medium. These reactions promote the formation or maintenance of protective oxides characteristic of the anodic protection of passivable metals.

Author Contributions: Conceptualization, R.S.S. and Á.M.; methodology, R.S.S. and Á.M.; formal analysis, R.S.S.; investigation, R.S.S. and Á.M.; resources, R.S.S. and Á.M.; data curation, R.S.S.; writing—original draft preparation, R.S.S.; writing—review and editing, R.S.S. and Á.M.; funding acquisition, Á.M. All authors have read and agreed to the published version of the manuscript.

Acknowledgments: National Council for Scientific and Technological Development (CNPq) and Coordination for the Improvement of Higher Education Personnel (CAPES).

Conflicts of Interest: The authors declare no conflict of interest and the funders had no role in the design of the study; in the collection, analyses, or interpretation of data; in the writing of the manuscript, or in the decision to publish the results.

\section{References}

1. Vargas, V.M.M.; Dalmolin, C.; Pezzin, S.H.; Oliveira, M.M.; Zamora, P.P. A Polianilina no Cenário Ambiental: Uma abordagem sobre fotocatálise heterogênea. Quím. Nova 2018, 41, 315-325. [CrossRef]

2. Armelin, E.; Meneguzzi, A.; Ferreira, C.A.; Alemán, C. Polyaniline, polypyrrole and poly(3,4ethylenedioxythiophene) as additives on organic coatings to prevent corrosion. Surf. Coat. Technol. 2009, 24, 3763-3769. [CrossRef]

3. Akabarinezhad, E.; Ebrahimi, M.; Sharif, F.; Attar, M.M.; Faridi, H.R. Synthesis and evaluating corrosion protection effects of emeraldine base PAni/clay nanocomposite as a barrier pigment in zinc-rich ethyl silicate primer. Prog. Org. Coat. 2011, 1, 39-44. [CrossRef]

4. Panossian, Z.; Almeida, N.L.; Sousa, R.M.F.; Pimenta, G.S.; Marques, L.B.S. Corrosion of carbon steel pipes and tanks by concentrated sulfuric acid: A review. Corros. Sci. 2012, 58, 1-11. [CrossRef] 
5. Duarte, G.W.; Naspolini, A.M.; Tachinski, C.G.; Consenso, E.C.; Mello, J.M.M.; Silva, L.L.; Fiori, M.A. Study of the effect of synthesis parameters in the electrical conductivity of the composite poly (vinylidene fluoride)/polyaniline. Matéria (Roi J.) 2017, 22, e11859. [CrossRef]

6. Jaymand, M. Recent progress in chemical modification of polyanline. Prog. Polym. Sci. 2013, 9, 1287-1306. [CrossRef]

7. Skotheim, T.A.; Reynolds, J.R. Handbook of Conducting Polymers. Conjugated Polymers: Theory, Synthesis, Properties and Characterization; Taylor-Francis: New York, NY, USA, 2007.

8. Silva, R.S.; Aleman, C.; Ferreira, C.A.; Armelin, E.; Ferreira, J.Z.; Meneguzzi, A. Smart Paint for anodic protection of steel. Prog. Org. Coat. 2015, 78, 116-123. [CrossRef]

9. Zanotto, C.; Ratuchne, F.; Melquíades, F.L.; Marques, P.T.; De Castro, E.G. Síntese, Caracterização e Estudo Eletroquímico de Material Híbrido Baseado em Polianilina com $\mathrm{Fe}_{3} \mathrm{O}_{4}$. Revista Virtual Química 2017, 6, 2494-2505. [CrossRef]

10. Kumar, K.K.S.; Geetha, S.; Trivedi, D.C. Freestanding conducting polyaniline film for the control of electromagnetic radiations. Curr. Appl. Phys. 2005, 6, 603-608. [CrossRef]

11. Silva, R.S.; Cardozo, H.M.; Ferreira, J.Z.; Ferreira, C.A.; Meneguzzi, A. Filme Autosuportado de Polianilina Desdopada para Aplicações Anticorrossivas. Polímeros 2012, 3, 288-294. [CrossRef]

12. Nakamoto, K. Infrared and Raman Spectra of Inorganic and Coordination Compounds; John-Wiley: Hoboken, NJ, USA, 2009.

13. Tokarsky, J.; Maixner, M.; Peikertová, P.; Kulhánková, L.; Burda, J.V. The IR and Raman spectra of polyaniline adsorbed on the glass surface; comparison of experimental, empirical force field, and quantum chemical results. Eur. Polym. J. 2014, 57, 47-57. [CrossRef]

14. Trchová, M.; Morávková, Z.; Bláha, M.; Stejskal, J. Raman spectroscopy of polyaniline and oligoaniline thin films. Electrochim. Acta 2014, 10, 28-38. [CrossRef]

15. Morávková, Z.; Bober, P. Writing in a Polyaniline Film with Laser Beam and Stability of the Record: A Raman Spectroscopy Study. Int. J. Polym. Sci. 2018. [CrossRef]

16. Quillard, G.; Louam, G.; Bouisson, J.P.; Lefrant, S.; Masters, J.; Macdiarmid, A.G. Vibrational analysis of reduced and oxidized forms of polyaniline. Synth. Met. 1993, 1, 475-480. [CrossRef]

17. Mazzeu, M.A.C.; Faria, L.K.; Baldan, M.R.; Rezende, M.C.; Gonçalves, E.S. Influence of reaction time on the structure of polyaniline synthesized on a pre-pilot scale. Braz. J. Chem. Eng. 2018, 1, 123-130. [CrossRef]

18. Mazzeu, M.A.C.; Faria, L.K.; Baldan, M.R.; Rezende, M.C.; Gonçalves, E.S. Structural and Morphological Characteristics of Polyaniline Synthesized in Pilot Scale. J. Aerosp. Technol. Manag. 2017, 1, 39-47. [CrossRef]

19. Njoku, D.I.; Cui, M.; Xiao, H.; Shang, B.; Li, Y. Understanding the anticorrosive protective mechanisms of modified epoxy coatings with improved barrier, active and self-healing functionalities: EIS and spectroscopic techniques. Sci. Rep. 2017, 7, 1-15. [CrossRef]

20. Dudek, A.; Lisiecka, B.; Strzelczak, K. Assessment of the Quality of epoxy coating in the Automotive Industry. Tech. Trans. 2018, 11, 175-180.

21. Zhu, H.; Peng, S.; Jiang, W. Electrochemical Properties of PANI as Single Electrode of Electrochemical Capacitors in Acid Electrolytes. Sci. World J. 2013. [CrossRef]

22. Giroto, E.M.; Paoli, M.A. Transporte de massa em polímeros intrinsicamente condutores: Importância Técnicas e Modelos Teóricos. Quím. Nova 1999, 3, 358-368. [CrossRef]

23. Ballarin, B.; Boanini, E.; Montalto, L.; Mengucci, P.; Nanni, D.; Parise, C.; Ragazzini, I.; Rinaldi, D.; Sangiorgi, N.; Sanson, A.; et al. PANI/Au/ $\mathrm{Fe}_{3} \mathrm{O}_{4}$ nanocomposite materials for high performance energy storage. Electrochim. Acta 2019, 322, 134707. [CrossRef]

24. Guler, F.G.; Sarac, A.S. Electrochemical synthesis of Poly[3,4-Propylenedioxythiophene-co-N-Phenylsulfonyl Pyrrole]: Morphological, electrochemical and spectroscopic characterization. Polym. Lett. 2011, 6, 493-505. [CrossRef]

25. Mondal, K.M.; Prasad, K.R.; Munichandraiah, N. Analysis of electrochemical impedance of polyaniline films prepared by galvanostatic, potentiostatic and potentiodynamic methods. Synth. Met. 2005, 148, 275-286. [CrossRef]

(C) 2020 by the authors. Licensee MDPI, Basel, Switzerland. This article is an open access article distributed under the terms and conditions of the Creative Commons Attribution (CC BY) license (http://creativecommons.org/licenses/by/4.0/). 